\title{
OSVALdo ÁlvAREz RECUERda A SU PROFESOR
}

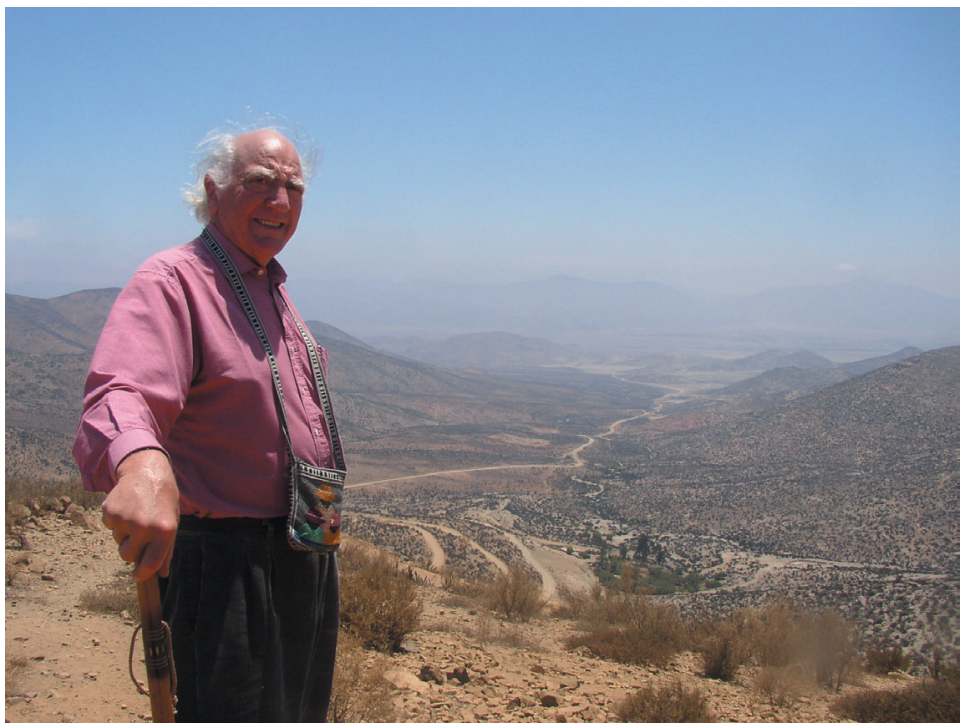

cursos escogí el laboratorio de David para hacer un seminario de investigación que era parte del currículo de los bioquímicos. Trabajé con David en un estudio de la microcirculación en la extremidad inferior del perro. Durante el seminario tuve el privilegio de conocer a otros investigadores presentes en el entorno, entre los cuales recuerdo especialmente a George Hodgson, Carlos

Congreso de la Sociedad Chilena de Ciencias Fisiológicas, Quinamávida, 1997.

DAVID Yudilevich fue el director de mi memoria para optar al título de Bioquímico que recibí en 1966 en la Facultad de Química y Farmacia de la Universidad de Chile. Conocí a David dos años antes cuando fue invitado a dar una clase sobre análisis de compartimientos en el curso de biofísica dictado por el Dr. Mario Luxoro. David nos llevó a su laboratorio que en esos años estaba en el $4^{\circ}$ piso del edificio de Física de la Escuela de Ingeniería de la Universidad de Chile, en la Avenida Blanco Encalada. David pertenecía a la división de física del Instituto de Ciencias, institución que posteriormente sería parte de la actual Facultad de Ciencias. Yo quedé fascinado con el uso de un computador digital, Lorentz, una maravilla que ocupaba varias piezas en un subterráneo de la facultad. También fueron de gran atracción los métodos matemáticos aplicados por David en su investigación, el Computador Análogo Donner y los equipos de medición de radiactividad, algunos de los cuales habían sido construidos por los ingenieros de la facultad. Cuando terminé de rendir mis
Martinoya, quienes junto a David fueron grandes inspiradores que influyeron fuertemente en mi formación como científico. David se mostró como un profesor muy interesado en mi trabajo y me ofreció hacer mi memoria de bioquímico bajo su dirección. Para ese entonces, David había construido un laboratorio, el Laboratorio G, en los terrenos de la Facultad de Medicina de la Universidad de Chile, en Independencia. Mi tesis fue un estudio del transporte agua y iones a través de la mucosa gástrica del perro, usando trazadores radiactivos. Una vez terminado el trabajo experimental y redactada la tesis, nos encontramos con que David no era profesor de la Escuela de Farmacia y necesitábamos un patrocinante. David, con su empuje irrefrenable, consiguió que Mitzy Canessa me patrocinara, y así pude conseguir mi título de bioquímico en 1966. La tesis fue publicada en los Anales de la Facultad de Química y Farmacia, y posteriormente en el American Journal of Physiology (Álvarez, O., Yudilevich, D. 1967. Capillary permeability and tissue exchange of water and electrolytes in the stomach. Amer. J. Physiol. 213: 315-322). Antes de recibirme de bioquímico, David me presentó al Decano de la Facultad de Ciencias, Gustavo 
Hoecker, y al final de la entrevista fui contratado como Ayudante de Investigación, en septiembre de 1995. Paralelamente con mi tesis participé en el proyecto de David para determinar la permeabilidad capilar del lecho coronario. Trabajamos duramente en este proyecto, sin importar los días feriados y las noches para completarlo y poder dar un buen Progress Report al NIH que nos estaba financiando. El trabajo salió bien y finalmente fue publicado en American Journal of Physiology (Yudilevich, D., Álvarez, O. 1967. Water, sodium and thiourea transcapillary diffusion in the dog heart. Amer. J. Physiol. 213: 308-314.). En el transcurso de la investigación resolvimos múltiples problemas metodológicos y una vez afinada la técnica pudimos hacer una gran publicación (Álvarez, O., Yudilevich, D. 1969. Heart capillary permeability to lipid insoluble molecules. J. Physiol (London). 202: 45-58). Me lleno de orgullo al recordar que una de las tablas de esa publicación fue citada íntegra en el libro de
Hugh Davson, que para mí era la Biblia en esos años. Hecha esta publicación, más algunas de menor importancia, David consiguió que hiciera un postdoctorado en la Universidad Yale en New Haven Connecticut, en el laboratorio de Peter F. Curran. Mandarme a un postdoctorado a Yale, con una beca Fullbright, sin tener un doctorado, es una de las acciones típicas de David. Una "yudilevichada" como él solía decir. Para él la carrera de Bioquímico de cinco años más una tesis era suficiente. David no se detenía en detalles con tal de conseguir su objetivo. De regreso a Santiago, mis años con David terminaron y salí a buscar mi independencia. Pero nunca se cortó el lazo que nos unió. David dejó en mí una marca imborrable.

David, fuiste un gran inspirador de mi juventud. Maestro querido, me despido de ti desempolvando estos recuerdos. Que descanses en paz.

OSVALDO ÁLVAREZ Mayo de 2006.

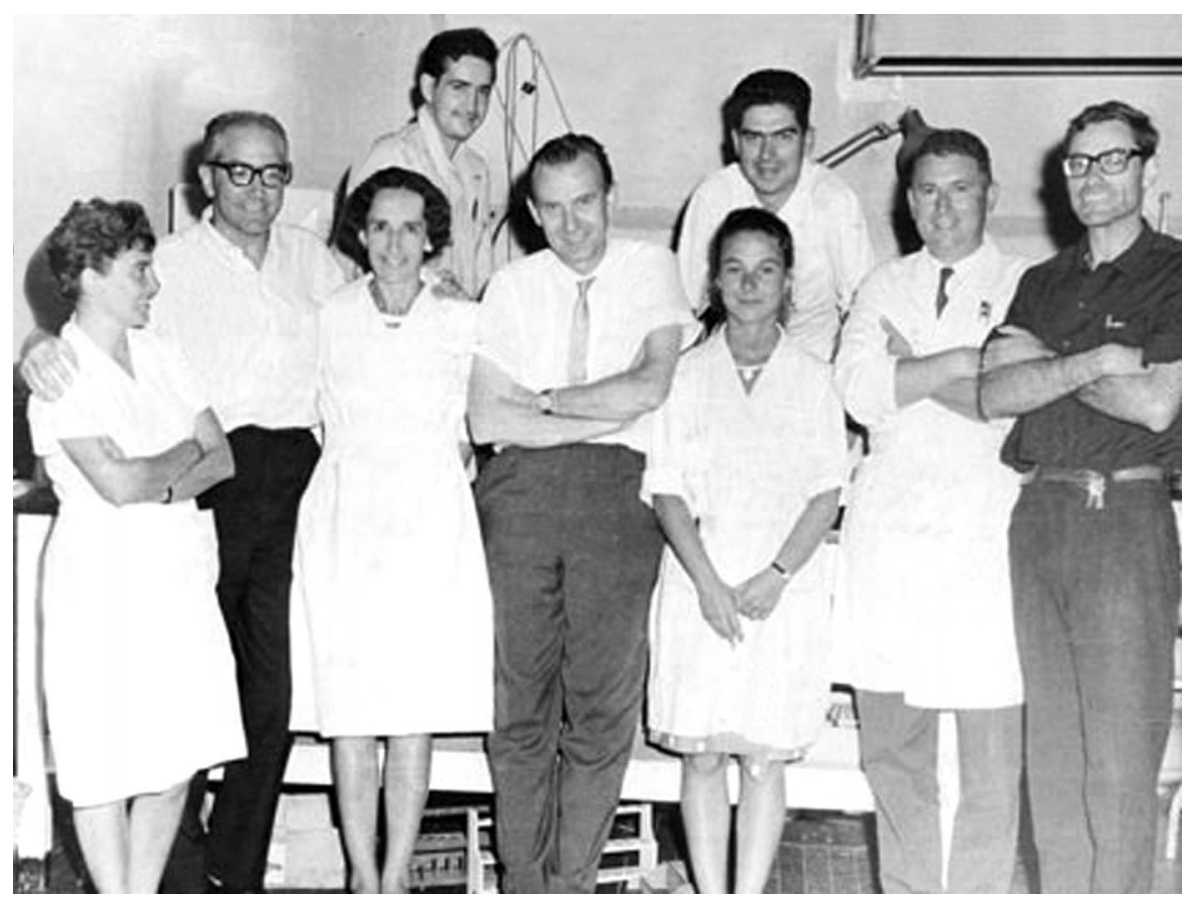

En la Facultad de Ingeniería de la Universidad de Chile. En primer plano, de izquierda a derecha: Rosa Jiménez, David Yudilevich, Irma Eskuche, George Hodgson, Maruja Pieber, Marcos Perretta y José Tohá. Fecha desconocida. 